UDC: 821.134.2(83).09 Eltit D.

821.134.2(82).09 Roffé R.

DOI: https://doi.org/10.18485/hispserb.2019.2.ch19

\author{
Ana Marković ${ }^{1}$ \\ Doctora por la Universidad de Barcelona \\ España
}

\title{
FORMAS DE RESISTENCIA Y SUJETO FEMENINO EN LUMPÉRICA DE DIAMELA ELTIT Y LA ROMPIENTE DE REINA ROFFÉ
}

\begin{abstract}
Resumen
Este trabajo aborda el tema de la escritura y la subjetividad femeninas como formas específicas de la resistencia al orden patriarcal y autoritario en las novelas Lumpérica (1983) de la autora chilena Diamela Eltit y La rompiente (1987) de la autora argentina Reina Roffé. Lumpérica es una novela experimental y fragmentaria centrada en la experiencia fantasmagórica de una mujer anónima que pasa una noche en una plaza de Santiago de Chile en la época de la dictadura de Pinochet. La rompiente es menos experimental que la novela de Eltit y describe la búsqueda de una voz auténtica femenina en tiempos de la última dictadura argentina. Hemos hecho un análisis de las dos novelas centrándonos en las formas de la construcción de la subjetividad femenina en relación con el uso del lenguaje y en las representaciones de las experiencias corporales de las protagonistas, tratando de establecer su conexión con las propuestas teóricas sobre la escritura del cuerpo como específicamente femenina. A pesar de sus diferencias estilísticas, las dos novelas tratan el tema de la dictadura desde una perspectiva muy subjetiva y personal, de manera indirecta, sin por ello perder su compromiso político y proponen la superación de las dicotomías
\end{abstract}

\footnotetext{
${ }^{1}$ anaamarkovic@yahoo.com
} 
entre lo personal y lo político a través de la representación de la experiencia específicamente femenina en tiempos de represión.

Palabras clave: Diamela Eltit, Reina Roffé, literatura femenina, escribir con el cuerpo, dictaduras en el Cono Sur.

\section{Introducción}

La novela Lumpérica de la chilena Diamela Eltit se publica en plena dictadura militar chilena, mientras que La rompiente de la argentina Reina Roffé pertenece a la época de la posdictadura argentina. Las dos novelas se centran en los personajes femeninos, interrogan el proceso de escribir, problematizan la voz autoritaria del logos represivo y patriarcal y describen una búsqueda de la identidad femenina a través de la sexualidad y la corporeidad, y a través del cuestionamiento de las estrategias narrativas. La crítica de la realidad política en estas obras es más bien indirecta mientras que la experiencia subjetiva femenina toma el primer plano, y con ella las cuestiones de la escritura, del cuerpo y del goce femeninos que buscan maneras de expresarse bajo el régimen dictatorial y en la sociedad patriarcal. En este sentido, Lumpérica y La rompiente ejemplifican la escritura femenina en su variante idiosincrásica latinoamericana, una escritura política y comprometida que rompe con las dicotomías entre lo personal y lo político.

Estilísticamente, sin embargo, las dos novelas son muy diferentes. Lumpérica es una novela muy hermética y experimental, una obra en deconstrucción y reconstrucción permanente, que cuestiona sus propios procedimientos sin cesar, y con trama casi inexistente. La rompiente, por otro lado, a pesar de su juego de voces narrativas y sus preocupaciones metaliterarias, presenta una historia más realista con referentes sociopolíticos más fácilmente identificables. Vamos a analizar dos obras por separado, enfocándonos en sus exploraciones de la subjetividad femenina como forma de resistencia política.

\section{Lumpérica y la escritura del cuerpo}

Según los críticos, Diamela Eltit pertenece a "la nueva escena literaria" chilena que se forma después del golpe del Estado, como la única mujer en este ámbito y movimiento literario. En palabras de Eugenia Brito, "la nueva escritura exhibirá hasta la exageración este carácter opresivo, 
victimario y reductor del sistema dominante, transgrediendo sus leyes e intentando liberar ese cuerpo ocupado" (1994: 11).

La novela Lumpérica, experimental y fragmentaria, que sale en 1983, representa una propuesta radicalmente diferente de ese género literario por su ruptura de códigos lingüísticos, su libre mezcla de registros estilísticos y la variación de procedimientos narrativos, su permanente problematización de la voz narrativa y por sus observaciones metanarrativas. A todo esto hay que añadir que se trata de la literatura de resistencia a pesar de ser una obra no testimonial, hermética y preocupada por el lenguaje como medio de representar el mundo. Lumpérica es una novela que destaca el paralelismo entre el cuerpo y el texto; más específicamente, se centra en el cuerpo femenino y en los cuerpos de la gente marginada, que se muestran como medios de resistencia y de la práctica textual subversiva. Como tal, la obra se puede leer dentro del contexto filosófico que posiciona el cuerpo y la escritura de la mujer firmemente fuera del logos masculino y entiende la escritura del cuerpo como una posible literatura femenina y un medio único y singular de la resistencia a la autoridad textual, social y política.

Lumpérica se centra, en líneas generales, en la mujer protagonista anónima, que pasa una noche en una plaza de Santiago de Chile, rodeada de los "desarrapados", "pálidos", "el lumpen", bajo la luz de un letrero que figura como una presencia fantasmagórica y ominosa a lo largo de la obra. La mujer no tiene nombre, la conocemos como L. iluminada a la que el letrero luminoso trata de inscribir significados. Mientras están en la plaza ocurren pocas cosas - hay gritos, caídas, heridas, quemaduras y movimientos continuos bajo la luz del letrero y los pocos eventos son presentados de manera fragmentaria, alucinatoria y repetidamente cuestionados junto con el cuestionamiento de los métodos de representar la realidad, sean estos lingüísticos y literarios o fílmicos. Las escenas se presentan como una suerte de espectáculo, una coreografía de los cuerpos sin nombres, regidos por los instintos y deseos difícilmente nombrables.

El motivo central de la novela parece ser la búsqueda de la identidad y del significado. Lo que ocurre en la plaza se denomina en el texto como una ceremonia del bautizo. La mujer protagonista y los hombres pobres y anónimos que concurren a la plaza carecen tanto de las características personales como de nombre. Los hombres son presentados de la siguiente manera:

[...] el frío en esta plaza es el tiempo que se ha marcado para suponerse un nombre propio, donado por el letrero que se encenderá y apagará, rítmico 
y ritual, en el proceso que en definitiva les dará la vida: su identificación ciudadana (Eltit 1983: 7)

El anonimato de los hombres en la plaza se relaciona con su marginación social y ciudadana; desterrados de los sistemas del poder político y social y sus correspondientes sistemas lingüísticos y significantes, despojados de la subjetividad, el texto les otorga una identidad inestable a través de un letrero que se convierte en el significante arbitrario y absurdo. Es más, acceder a un nombre y a una transcendencia simbólica les confiere vida a los que son tan solo cuerpos marcados por la inmundicia de su posición social:

[...] llegan los desarrapados de Santiago, pálidos y malolientes a buscar su área: el nombre y el apodo que como ficha les autorizará un recorrido [...]. Así serán nombrados genéricamente pálidos como escalafón provisorio. Esos que vienen desde los puntos más distantes hacia la plaza que prendida por redes eléctricas garantizan una ficción en la ciudad (Eltit 1983: 7).

A la inmundicia y la pobreza de los «pálidos» se oponen las luces del letrero que participan de la ficción que está en la base de una sociedad estructurada. De hecho, la novela se centra en las "ficciones" rivales, los discursos que compiten, las maneras de narrar y nombrar, y los revela todos como inestables y arbitrarios, a la vez que toda verdad aparece condicionada por las ficciones lingüísticas y sus sustentos sociales.

La mujer protagonista tampoco tiene nombre propio, y pertenece a la misma realidad social de los marginados sin identidad ni identificación ciudadana, aludida ya por el nombre de la novela: Lumpérica. Así es que su nombre también será decidido en relación con el letrero luminoso: "Le ratifica el nombre en dos colores paralelos, el luminoso ampliado sobre el cuerpo escribe L. Iluminada y rítmicamente va pasando la cantidad posible de apodos: le escribe tránsfuga y la letra cae como toma fílmica" (Eltit 1983: 8).

La L. iluminada y los pálidos, todavía sin nombres personales e individualizados, definidos a través de su relación con un símbolo del orden y de la autoridad, prosiguen en la búsqueda de maneras de expresarse con sus cuerpos sacudidos, orgiásticos, balbuceando y sin hablar, oponiendo por ende un lenguaje corporal y primordial a los que tienen el poder de nombrar y ofrecer un sentido a través de la ficción comercial y autorizada por el Estado. El encuentro de la plaza se describe como "festín" y lo que sigue son gritos, golpes y expresiones 
del placer erótico y vital constituyéndose en un único lenguaje posible para los que lo hablan. Se nos presenta una imagen de lo abyecto donde la descomposición del sujeto femenino va unida a la exploración de una sexualidad transgresiva y a un cierto exceso lingüístico en marcado contraste con las seguridades de los discursos hegemónicos: "Todas sus identidades posibles han aflorado por desborde - clavando sus puntos anatómicos - sobrepasándola en sus zonas" (Eltit 1983: 9).

Estamos a la vez frente a un texto literario y frente a un espectáculo presentado como tomas fílmicas y en forma de comentarios a las escenas de una película. Se nos presenta una construcción explícitamente artificial, una realidad que aunque manifestada a través de los cuerpos, gritos y gemidos, parece tan solo una de las posibles realidades, una suerte de performance a la vez espontánea y ensayada, que indica una alienación lingüística a pesar del carácter subversivo del lenguaje corporal de los personajes. El texto está repleto de los comentarios metaliterarios: "Y dime ahora qué se siente estirada en el banco, cubierta de plástico, a plena espalda de la literatura" (Eltit 1983: 96). También hay muchas referencias explicitas al espectáculo, sin comentarios autoriales sobre las motivaciones internas de los gestos de la protagonista: "[...] saben que ella necesita ese espacio preciso para mostrar su espectáculo. Ha adquirido otra identidad: por literatura fue" (Eltit 1983: 16). La subjetividad femenina pasa por las posibilidades expresivas dentro de los límites de un sistema opresivo: es una interacción y lucha de signos. Además, hay fragmentos de la novela escritos en el estilo de poesía vanguardista, de carácter muy personal y otros en forma de un interrogatorio policial sobre las cosas banales del funcionamiento de la plaza. A veces parece un texto eternamente problematizado, borrado y reescrito, con la ausencia de detalles objetivos y descriptivos aparte de los más básicos. Hay alusiones indirectas al terror, a los hospitales y golpes eléctricos que forman el contexto histórico y político de la novela.

La subjetividad de la protagonista, dado su posicionamiento fuera del logos autoritario, entra en el campo de lo animal y de lo erótico como expresión de una fuerza instintiva y primordial. Así es que la mujer repta por la plaza, deja su baba detrás de sí, muge como una vaca, es una yegua que trota o galopa, relincha o aúlla, buscando provocar una reacción de los hombres pálidos. También se opone con su espectáculo animalista a la fuerza del letrero:

Pero ¿cómo se tienta a la luz eléctrica? ¿bajo qué mecanismo la perturba? si relincha, si muge o brama, si se estira perezosa como gata, si se arrastra 
como insecto bajo los bordes del farol, si croa, si pía, logrará efecto? hará que ese cable la cabalgue? interrumpirá la luz por un momento? (Eltit 1983: 59)

Lo animal viene a ser una forma de resistencia para los que no tienen acceso a la subjetividad autorizada por los signos y símbolos sociales. Según Julia Kristeva (2006: 21), "lo abyecto nos confronta con esos estados frágiles donde el hombre erra en los territorios de lo animal" y precede a la formación del sujeto. Esta vuelta a lo animal, y las imágenes de lo abyecto en la literatura de las mujeres no tienden a representar una simple regresión psicológica de los sujetos que no tienen el poder, sino que abre una nueva posibilidad de reconfigurar la subjetividad femenina como subversiva respecto al logos patriarcal, formándose de este modo como sujeto histórico y cultural. No es sorprendente entonces que las teorías de la escritura femenina, desde Luisa Valenzuela en el contexto latinoamericano hasta Hélène Cixous en el ámbito del feminismo francés, insistan en lo corporal, lo fisiológico e incluso lo animal en contraste con el orden institucional de un logos falocéntrico. Así Helene Cixous habla sobre un salvajismo de la mujer que amenaza con destruir el orden social: "En relación al orden masculino, por sumisa y dócil que ella sea, sigue existiendo la posibilidad amenazante del salvajismo, la parte desconocida de todo lo doméstico" (Cixous 2001: 53). Ese salvajismo es visible en la actuación frenética de la protagonista.

Al imaginario animal se unen referencias a los gritos, cortes en los brazos, caídas y heridas de la protagonista. Se golpea la cabeza, se quema la mano, gime y grita comunicándose de esta manera con los desarrapados. Su lenguaje es un lenguaje del dolor, de la escisión, de la ruptura y el límite que aluden a la situación social de Chile de la época. Como dice Eugenia Brito: "La escritura entonces 'raja' la piel: es el producto de una entrada en el cuerpo mismo sitiado, resistente y doloroso de la protagonista. La escritura exige, pues, un acto sacrificial, del cual puede advenir la muerte o la locura" (1994: 123). Ese lenguaje primigenio y no verbal refleja la idea de Héléne Cixous sobre el prelenguaje del inconsciente como base de la escritura femenina.

La protagonista escribe las palabras "quo vadis" en el centro de la plaza, con la ayuda del lumperío. Es la pregunta que se puede leer en clave existencial, pero también en clave de la situación política chilena en los tiempos de la dictadura, la que la une con el lumperío en una desesperación colectiva y una sensación de solidaridad. 
La novela acaba con un capítulo narrado linealmente con lenguaje descriptivo y claro, que describe a la protagonista en la plaza, fascinada con el letrero, mirándose en el espejo que saca de su bolso, después de lo cual corta su pelo. La búsqueda de la identidad, ahora menos frenética y enloquecida, acaba con ese pequeño gesto de rebeldía, dirigido en contra de los imperativos de la feminidad.

\section{La rompiente, lo personal y lo político}

La novela La rompiente de la argentina Reina Roffé se publica en 1987, unos años después del fin de la última dictadura argentina. Mucho menos experimental y hermética que la novela de Eltit, presenta sin embargo un procedimiento narrativo complejo y, tal como en la obra de Eltit, alude a la época de la dictadura oblicuamente, en este caso a través de las memorias de la protagonista exiliada en un país desconocido, y a través de una novela dentro de la novela.

Igual que en Lumpérica, el punto de partida es subjetivo: la protagonista padece de una falta de energía vital y su mirada hacia el pasado se presenta más bien como una historia personal que como un intento de indagar en lo social y político de sus circunstancias.

En el prólogo a la obra, titulado "Itinerario de una escritura", Roffé expone sus dudas sobre el proceso creativo que se derivan específicamente de su condición de mujer. Describe sus dos novelas que precedieron a La rompiente, la primera personal y subjetiva, y la segunda que, según ella, escribió en clave realista, bajo la presión social, para escapar los prejuicios sobre la escritura femenina y por ende "traicionando el mensaje individual, subjetivo, 'femenino'” (1987: 10) En La rompiente vuelve a la literatura más personal aunque trata un tema de transcendencia social, esta vez de manera consciente y luchando en contra de los prejuicios:

Como mujer que escribe había recibido el bagaje de una serie de dichos y entredichos: que la escritura femenina carece de nivel simbólico, que está sujeta al referente, que abusa de interrogantes, repeticiones y detalles, que se caracteriza por un tono de enojo y resentimiento. [...] vi el peligro al que se expone la escritora que, buscando aprobación, toma una voz prestada para responder a las expectativas y exigencias del medio, de la crítica y de ciertos interlocutores que funcionan como marco de referencia. [...] La rompiente es un paso más [...] donde recupero - paradójicamente el deseo que sustentó la escritura de mi primera novela: la integración, por medio de lo escrito, de un mundo personal alienado y en fragmentos (Roffé 1983: 10-11). 
La rompiente es una historia subjetiva que se desarrolla en el marco de una historia política; los dos niveles de la obra de hecho son inseparables. La crítica social y política pasa por lo personal y subjetivo, y en esta fusión, acaso, hay que buscar la especificidad de la literatura femenina que trata los temas de dictadura y posdictadura en el Cono Sur.

La novela de Roffé está dividida en tres partes y tiene una compleja estructura narrativa, con una variedad de voces y la presentación fragmentada de los hechos que tienen que ver con una historia amorosa de la protagonista a la vez que con el terror del Estado en la época de la última dictadura argentina. Es una novela que presenta, como quiere la autora en su prólogo, "un mundo personal alienado" dentro del contexto nefasto de las circunstancias político-históricas argentinas de la época, pero ante todo, es una novela sobre la búsqueda de la propia voz - y con ello, de la voluntad de vivir - por parte de la protagonista-escritora en un mundo represivo.

En la primera parte una voz narrativa anónima recuenta la historia que le ha contado la propia protagonista, exiliada desde hace años en un país lejano y padeciendo de la "anhedonia", que se define como "enfermedad cuyos síntomas son infelicidad y no encontrar el placer en las cosas que otros disfrutan" (Roffé 1987: 22). En su nuevo país lleva una vida monótona en los suburbios, en compañía de una mujer mayor.

En la segunda parte de La rompiente se nos presenta la novela escrita por la protagonista, una novela autobiográfica que nos ayuda a reconstruir su vida pasada y la situación del país durante la dictadura. En el proceso de la relectura de su propio texto, la protagonista expresa sus dudas e incertidumbres sobre el procedimiento narrativo e incluso también sobre los hechos narrados, que oscilan entre la ficción y la realidad, la memoria y el olvido, así que la novela queda repleta de inquietudes que reflejan el momento histórico y la represión del Estado.

Las dudas de la protagonista-escritora convertida en la editora de su propia obra tienen que ver, en igual medida, con el problema de los géneros literarios y sus posibilidades expresivas. Así es que ella narra cómo dejó de escribir poesía lírica y personal en nombre de un compromiso político, presionada por un amigo y por su amante, que luego será su marido, los dos hombres significativamente mayores que ella, es decir, por la autoridad masculina: "Fue, cuando buscando aprobación, renuncié a lo que quería decir y tomé una voz prestada que, al no pertenecerme, se volvió en contra de mí misma" (Roffé 1987: 58) La dicotomía entre lo personal y lo político, entre lo sentimental y lo histórico, se manifiesta 
también en su reflexión sobre la intención que la guía al escribir su novela autobiográfica:

Mi pretensión - ahora resulta obvia - bordeaba más el lado existencial que otra cosa; quería que se me adscribiera a la corriente intimista, subjetiva, lírica [...]. No confesé que en el fondo de mi corazoncito intentaba valerme de agudos artificios para dar, mediante la gran metáfora, los oscuros padecimientos de la época (Roffé 1987: 44-45).

La historia central, la del primer plano, es una historia del amor de la joven escritora con un crítico literario, que corresponde al dominio de los estereotipos femeninos y de la literatura sentimental tradicionalmente codificada como femenina. En ella se describe la relación romántica de la protagonista con un hombre da mayor edad y prestigio y una relación sexual que a momentos refleja la desigualdad de sus posiciones sociales. Sin embargo, la escritura auténtica - femenina - es, en la propuesta de Roffé, justamente la que supera las dicotomías falogocéntricas que relegan lo personal a la esfera de lo intranscendente y apolítico y se relaciona estrechamente con la recuperación de la energía vital en un mundo alienante y hostil para la mujer.

La pasividad y la marginación social de la protagonista se notan en su incertidumbre con respecto a los hechos claves de la historia la muerte de los dos personajes más cercanos a ella. Su amigo se cree perseguido, se alude a una posible paranoia por parte del personaje, a su locura; su muerte podría ser un asesinato pero el texto no lo deja claro. Cuando los hombres discuten sobre la persecución, ella queda excluida. Refiriéndose a sí misma en tercera persona, la narradora dice: "[...] su sola presencia profana el sagrado lugar de la amistad masculina" (Roffé 1987: 73). La incertidumbre también parece el dominio de la mujer y de la escritura:

Y ni bien pierdo por completo la cabeza, se me inflama el corazón, entro en el proyecto confesional, me deleito con mis fantasmas, usted, súbitamente - hallándome en la éxtasis de mi goce - vuelve unas páginas atrás, indaga en busca de un dato cierto. Lamento, sinceramente, que no pueda complacer su demanda [...] La incertidumbre reina. (Roffé 1987: 55)

La tercera parte de la novela narra los hechos y los años que preceden al exilio de la protagonista, ya separada del marido y entregada completamente a la soledad, confinada en su casa, sin ganas de vivir y sin la inspiración para escribir. El ambiente del país es ominoso, ella empieza 
a sentir miedo a la persecución y a presenciar las razias de policía. Se siente lo más segura cuando está en la cama. Su anhedonia, la falta del placer, influye directamente en su escritura, que se revela otra vez como un acto corporal, de una entrega vital y sensual. Su novela fue escrita durante los tiempos de amor y de la actividad política y literaria, sus ganas de abandonar el país tienen que ver con la esperanza de volver a escribir: “¿Hallaré, a donde vaya, el esplendor de una voz?”. La novela termina con la imagen de la sangre menstrual: "El dolor se disipa como si este esplendor incierto contuviera una substancia benévola que pondrá otra vez su vida en juego. Ahora, sangra" (Roffé 1987: 124). La sangre menstrual, es decir, su cuerpo femenino le abre la posibilidad de la escritura.

En este sentido, la novela de Roffé encaja dentro de las propuestas teóricas de la literatura femenina como una escritura del cuerpo. La protagonista de Lumpérica de Eltit también habla más que nada con el cuerpo, pero un cuerpo rebelde y enloquecido, entregado a un erotismo descontrolado. La protagonista de La rompiente, más bien pasiva y cada vez más alienada de su entorno, sumergida en un ambiente de miedo y persecución, queda sin fuerzas de reaccionar frente al horror y pierde el control tanto de su cuerpo como de su espíritu. Así, por ejemplo, cuando llega a ella el rumor de la muerte de su amigo, lo único que siente son ganas de dormir. Las escenas del goce erótico se reemplazan por las escenas de una vida de enferma que no sale de su cama. La degradación de la experiencia corporal sigue el desarrollo de la historia, que iniciada en clave sentimental pasa a ser más claramente una historia social y política. Y es precisamente su cuerpo femenino lo único que le ofrece alguna esperanza al final de la novela. Como destaca Mary Beth TierneyTello, aquí el cuerpo femenino sirve como fundamento no tan solo de una escritura, sino de la subjetividad femenina:

The much theorized and poeticized activity of "writing the body" is not here a goal in itself. The female body [...] provides the protagonist/writer with the space of her own that she needs in order to imagine a female subjectivity and, perhaps even more significantly, to imagine that female subjectivity in a politically inflected world ${ }^{2}$ (1996: 171).

\footnotetext{
${ }^{2}$ La frecuentemente teorizada y poetizada actividad de "escribir el cuerpo" no es aquí un fin en sí mismo. El cuerpo femenino otorga a la protagonista/escritora el espacio propio que ella necesita para poder imaginar la subjetividad femenina y, quizás aún más significativamente, para imaginar la subjetividad femenina en un mundo marcado por la política [La traducción es mía].
} 
También es interesante notar que, como señala la crítica Nuria Girona Fibla, en la novela argentina de los años ochenta hay una presencia importante del motivo del cuerpo dolido o enfermo, que llega a ser una metáfora de los efectos de la dictadura: "No se puede escribir sobre algo que no haya dejado una marca y estas obras se articulan a partir de las marcas del cuerpo, sin decir que esas marcas son de la dictadura" (1995: 163).

En la escritura femenina sobre la dictadura el enfoque en el cuerpo tiene un significado específico. Marginada por el mundo patriarcal y represivo, sin voz propia, la mujer parte de su experiencia corporal para entrar en el mundo del logos y de lo simbólico. Lo personal, lo corporal, la experiencia subjetiva de la mujer en una sociedad en la que se encuentra doblemente oprimida, justamente añaden otra dimensión política a la descripción de la realidad de la dictadura.

En resumen, La rompiente presenta los años del terror de la última dictadura argentina partiendo de la situación personal de la mujer que ha perdido el deseo de vivir y de escribir. Participante casi involuntaria de la actividad político-literaria al inicio de su novela autobiográfica, rodeada por hombres que la introducen en su mundo, acaba su estancia en Argentina sola, enfocada en su cuerpo y con una nueva esperanza de encontrar su propia voz. La perspectiva personal no resta la transcendencia al relato político; el terror del Estado se refleja en la descomposición de la vida de la protagonista y en la incertidumbre narrativa de su novela. El miedo permea la memoria misma y corroe sus posibles verdades, la línea entre las paranoias, los delirios y las persecuciones reales se difumina y con ello la posibilidad de una literatura realista y testimonial en el sentido tradicional. Lo que queda es una literatura confesional y confusa, que se cuestiona a sí misma y se sirve de los códigos adscritos a lo femenino, sin perder por ello su impacto.

\section{Conclusiones}

Tanto Lumpérica como La Rompiente representan un intento específico de la literatura femenina de su época de relacionar los temas de la represión política con los temas más globales sobre el poder, lo femenino y el lenguaje. Las dos se componen de una narración fragmentaria y personal con la protagonista en primer plano. Lumpérica es más experimental y hermética, casi todo un cuestionamiento de la posibilidad misma de representar la realidad, especialmente en condiciones represivas. Es una escritura del cuerpo por excelencia. Por 
otro lado, La rompiente, a pesar de su complejidad narrativa, presenta una historia más realista, con referencias más explícitas a las circunstancias políticas del fondo, aunque estas no se mencionan frecuentemente y se reflejan más bien en el deterioro de la energía vital de la protagonista y de su relación sentimental. Las dos obras destacan lo inseparable de lo político y de lo personal y la posibilidad, o más bien, la necesidad de la escritura femenina de cuestionar y subvertir la realidad sociopolítica junto con el logos mismo, de signo masculino.

\section{BIBLIOGRAFÍA}

Brito, Eugenia. Campos minados: literatura post-golpe en Chile. Santiago: Cuarto Propio, 1994. Impreso.

Cixous, Hélène. La risa de la medusa. Ensayos sobre la escritura. Barcelona: Anthropos, 2001. Impreso.

Eltit, Diamela. Lumpérica. Santiago de Chile: Las Ediciones del Ornitorrinco, 1983. Impreso.

Girona Fibla, Nuria. Escrituras de la historia: La novela argentina de los años ochenta, Valencia: Universitat de València, 1995. Impreso.

Kristeva, Julia. Poderes de la perversión: Ensayo sobre Louis-Ferdinand Céline, México: Siglo XXI, 2006. Impreso.

Girona Fibla, Nuria. Escrituras de la historia: La novela argentina de los años ochenta, Valencia: Universitat de València, 1995. Impreso.

Roffé, Reina. La rompiente. Buenos Aires: Puntosur, 1987. Impreso.

Tierney-Tello, Mary Beth. Allegories of Transgression and Transformation: Experimental Fiction by Women Writing Under Dictatorship. Albany: State University of New York Press, 1996. Print. 


\title{
FORMS OF RESISTANCE AND THE FEMALE SUBJECT IN LUMPÉRICA BY DIAMELA ELTIT AND LA ROMPIENTE BY REINA ROFFÉ
}

\begin{abstract}
Summary
This paper deals with the topic of female writing and subjectivity understood as specific forms of resistance to the patriarchal and authoritarian order in the novels Lumpérica (1983) by Chilean writer Diamela Eltit and La rompiente (1987) by Argentinian writer Reina Roffé. Lumpérica is an experimental and fragmented novel describing the phantasmagoric experience of an anonymous woman, who spends one night in a city square In Santiago de Chile during the Pinochet's dictatorship. La rompiente is less experimental than Eltit's novel and describes the search for an authentic female voice during the last Argentinian dictatorship. Our analysis focuses on the construction of female subjectivity in relation to language and on representations of corporal experience of the protagonists, and tries to establish the connection with theoretical conceptions of writing with the body as a specifically female form of writing. In spite of its stylistic differences, the two novels approach the subject of dictatorship indirectly, from a very personal and subjective point of view, but that doesn't lessen their political critique. The dichotomy between the personal and political is overcome through the representation of specifically female experience during the times of repression.
\end{abstract}

Keywords: Diamela Eltit, Reina Roffé, female literature, writing with the body, dictatorships in The Southern Cone. 